\title{
Socioeconomic Arguments in the Discourse on Girl-Child Right to Education in Nigeria
}

\author{
Wilson Diriwari ${ }^{1}$ \\ ${ }^{1} \mathrm{PhD}$ (Brunel University, London) LLM (Lagos State University), LLB (Obafemi Awolowo University), Solicitor \\ (England and Wales). Lecturer in Law at Niger Delta University, Nigeria \\ Correspondence: Wilson Diriwari, Niger Delta University, Nigeria.
}

The author accepts full responsibility for any errors or omissions in this paper and welcomes correspondence to wods234_ola@yahoo.com,wilson@wsolicitors.co.uk.

Received: January 27, 2022

Accepted: February 25, 2022

Available online: February 25, 2022

doi:10.11114/ijsss.v10i2.5464

URL: https://doi.org/10.11114/ijsss.v10i2.5464

\begin{abstract}
It is evident that the deprivation of girl-children of their rights is a deeply-rooted phenomenon in societies across the globe that has thwarted all attempts to quell it. This article examines the enduring question of the deprivation of girl-children of their right to formal education in Nigeria. It shows that the right to formal education is deemed a fundamental human right and is thus non-negotiable and inalienable. The article then evaluates the determinants of this deprivation in Nigerian society and demonstrates that economic factors constitute the common denominator. The article also shows that cultural factors and the current COVID-19 pandemic are elements underpinning the perpetuation of the deprivation of girl-children of their right to education. The article demonstrates the destructive effects of the phenomenon on Nigerian society, the imperativeness of modernisation, and how the obligation to comply with international legal standards has placed the country in a complex situation. Its perpetuation in Nigeria has become a matter of great concern for authorities and other stakeholders. Hence, the article concludes that there is a need for a paradigm shift in approaches to the question in terms of law and policy responses.
\end{abstract}

Keywords: child rights to education, girl-child rights to education in Nigeria, determining factors, international legal standards, law and policy response

\section{Introduction}

Education remains the most important pathway to social and economic self-realisation. As such, it must be available to everyone regardless of race, gender, or social condition. This is so pertinent that the discourse on education has gained a universal impetus. Consecrating access to education as a universal right, members of the newly established United Nations enshrined it in the Universal Declaration of Human Rights (1948). This endeavour was followed by elaboration in national and other international legal instruments that promote and protect the right to education. While numerous legal instruments include provisions on the right to education, it is worth noting that they also place greater emphasis on gender equality in accessing education. Hence, countries that willingly ratified and domesticated various instruments are deemed promoters and protectors of both the right to education and gender equality in accessing education.

Paradoxically, the right to education of girl-children is not upheld in many countries. Girl-children are thus deprived of their right to formal education. It is observed that where a choice must be made for schooling, boys are preferred to girls. Behind this choice are several factors that underpin the phenomenon of the deprivation of girl-children of their right to education. These factors are not determined by the compulsion to make a choice. Instead, they are integral aspects of socio-cultural and religious settings in Nigeria and are subject to unpredicted phenomena such as the current Covid-19 pandemic, which has struck most countries, including Nigeria. Hence, the nature of the problem has created a challenging environment for authorities and other stakeholders in the country. Indeed, Nigeria is among the countries struggling to find a definite response to the deprivation of girl-children of their right to formal education.

\section{Evaluation of the Determinants}

The current evaluation of the determinants of the deprivation of girl-children of their right to formal education is aimed at identifying the sociocultural factors that underpin the phenomenon and guarantee its perpetuation. 


\subsection{Cultural and Religious Factors}

In any attempt to demonstrate the perpetuation of the deprivation of girl-children of their right to formal education, and evaluation of cultural factors is essential. Culture and tradition have long been thought to be factors hindering the realisation or establishment of (what are considered) actions or endeavours that are said to be exogenous institutions or attributes of western colonisers. From this standpoint, the acceptance of exogenous cultures remains an equation with several unknowns. Cultural factors are often moulded into traditional perceptions. It is worth recalling, with regard to tradition and culture, that traditions indicate the beliefs of a group and behaviour passed down from one generation to another. By contrast, culture indicates characteristics shared by an entire group that have been gathered or constructed throughout its history. A cultural practice that women or girls should not be prioritised or should be deprived of their right to formal education rests on traditional views that women do not merit embarking on education and professional life.

Discourse on the fate of girls and women in many societies has often shown that their social categorisation cannot be changed, in that members of the feminine sex are 'naturally' lower-class human beings. Oyigbenu (2010) observed that the girl-child, and women worldwide - especially in Nigeria - have their destiny sealed from birth by tradition and culture, on account of their biological sex. Oyigbenu (2010) emphasised that women have been called the 'weaker sex' to justify societal discrimination and their oppression. As a result, they must remain silent hewers of wood and drawers of water, bearers of children, and toilers in arduous labour from sunrise to sundown. Although Oyigbenu made a pertinent observation about the fate of women and girls in Nigeria, there is no indication that the the misery of women and girls will end soon. Tradition and culture are regarded as factors underpinning the social categorisation of or discrimination against women and girls. This social discrimination certainly takes a toll on girl-children regarding the enjoyment of their right to education in Nigeria.

The main argument in many parts of the world, including Nigeria, regarding neglect of girls' education is the belief that any education women acquire would only be useful in their marital homes (Mulkah et al., 2015). Such an argument promotes the views of traditional conservatives and reflects a parochialism littered with gender bias. The argument does not indicate evidence to demonstrate that men are far better than their female counterparts when given equal opportunities; therefore, reducing the usefulness of women to that of the marital home is unfair and unjustified. Unfortunately, it appears to be the leading argument in Nigerian communities where girl-children are deprived of their right to education.

Paradoxically, the discourse on girl-children's rights to formal education has been maintained by several scholars, yet they have not been able to propose an adequate pedagogical approach to the eradication of the problem in Nigeria. It appears that most scholars who undertake research about some Nigerian communities' traditional and cultural perceptions and practices regarding the question of women and girls are more interested in the narration of the situation. while expectations are high as to their contribution to the discourse, their works do not provide a comprehensive approach to eradicating the phenomenon of the deprivation of girl-children to their right to education.

Godiya Allanana observed that in some Nigerian traditional communities, women are reduced to mere infidels and second-class citizens; hence, there is the general belief that the best place for women is in the 'kitchen'. This trend has brought about tremendous misrepresentations of women, from the family to the societal level. Nigerian society is patriarchal in nature. This is a significant feature of traditional culture (Makama, 2013), making the situation more complex because misrepresentation is based on prejudice and wrongful perceptions. The question here is whether a deeply rooted perception can easily allow for changes enabling girls to fully enjoy their rights in Nigeria, including their critical right to formal education, which should be an inalienable right.

Kainuwa and Yusuf (2013) emphasised that the lack of girls' education should be a matter of great concern for every nation in the world, as this discrimination against girls makes it difficult for them to exercise their rights, exposing them to victimisation through various traditional and cultural practices. A universal pattern of traditional and cultural perceptions about girls' education exists, but it is more dominant in countries such as Nigeria, where traditional and cultural views are strong regarding modernism. Modernism here stands for the necessity of engaging in the dynamic of the coloniser's views and perceptions of life in society. Taking this from the historical point of view, it is evident that in Nigeria, having been colonised by Great Britain, it was an imperative for the colonised country to adhere to new practices and values. Formal education for both genders was an aspect of the new values transposed by colonisation. The question remains as to whether the traditional environment was favourable to such a transposition of exogenous values.

Sixty years after independence from Great Britain, the question of girls' right to formal education is still in the spotlight. Logically, having been placed in the dynamic of the harmonisation of views on the question of gender equality in modern society and the necessity to accept and protect girls' right to formal education, traditional communities and conservatives in Nigeria should have responded positively to inclusive education (UNICEF, n.d.), which is considered a valid and comprehensive approach to enhancing socio-economic development of Nigeria. In an attempt to understand the reason for the lack of improvement in girl-children's access to formal education, Ofoha (2013) enquired as to why the situation 
has persisted despite efforts by governments, international organisations, and NGOs to boost female education over the years. Ofoha (2013) observed that the real issues had not been appropriately addressed in the largely unexplored area of gender stereotypes. In Nigerian society, gender stereotypes are pronounced in every aspect of human activity. Several authors have pointed to this and other issues that interact to affect female access to education (Ofoha, 2013). Again, it must be understood that deeply rooted traditional and cultural considerations remain an undisputed impediment to the enjoyment of girl children's right to education in Nigeria. The question of gender stereotypes itself has its roots in traditional and cultural perceptions of the position of women and men within some Nigerian communities.

Obviously, the problem of gender equality is prevalent in most Nigerian communities, and it constitutes a driving force behind the deprivation of girl-children of their right to education. Obanya (2004) is of the view that there is a gender gap between boys and girls and that the gender gap widens as education increases.

A religious factor is prevalent in the approach taken by most northern communities in Nigeria. The population in the north are essentially Muslims, and the practice of Islam has led to the transposition of Islamic values into community life. It is noteworthy that Sharia is applied in the northern part of Nigeria. This does not mean that federal or state laws are not implemented. Instead, due to the dominant religion, Islam, and the fact that Nigeria is a legally pluralistic country, the application of Sharia is recognised at the federal level. The issue arising here is that religious views have negatively impacted the exercise of girl children's right to formal education.

The deprivation of girl-children of their right to formal education is evidenced by several practices or stereotypes that have often been justified by religious principles. Whether or not these views are distorted, the factual evidence of the destruction of girl children's lives and the deprivation of their right to formal education is incontestable. General observations of girls' education in northern Nigeria reveal that parents' religious views drive the negation of girl children's access to formal education.

There is a general perception among Muslims in northern Nigeria that formal education is for boys. In attempting to grasp this issue from an Islamic perspective, it has been difficult to justify such beliefs, and there are many contradictions. In this context, Sulaiman (2016) observes that Islam has, from its inception, placed a high premium on education and has enjoyed a long and rich intellectual tradition. Education occupies a significant position within Islam, as evidenced by more than 800 references in Al-Qur'an. The importance of education is repeatedly emphasised in Al-Qur'an, with frequent injunctions, whether such knowledge is Islamic or western (Sulaiman, 2016). This argument is flawed because although there be references to education in Islam, this does not, in itself, support the contention that Islam supports the right of girl-children to education. This position is similar to the view canvassed by Saeed regarding Islamic support for the treatment of vulnerable groups with care and respect. Of course, you can still treat this vulnerable group with care and respect and still refuse their right to education, which is critical to self-actualisation.

From the perspective of reconciling Islamic perceptions of human rights and international law, Saeedand et al. ( 2018) argued that it is possible to conceive of human rights norms as arising out of international law and thus binding on all states by agreement. Saeed maintained that the Islamic tradition has a long history of protecting the rights of children. According to him, the Qur'an and the Prophet both emphasised the need to treat vulnerable people in the community, such as the old and the very young, with special care and respect. This argument does not hold water because the reference to treating the vulnerable with care and respect does not in itself indicate that the issue of gender or the female right to education has long been promoted in Islamic tradition.

The cocodign view is that education is important for both boys and girls in any society and it must be recalled that education is a fundamental right for all including girls and women. Women according to UNESCO (2015) through education could contribute to the improvement in the standards of living not only to their immediate families but to the society in general. Girls' education does not only empower girls, but it is the best investment in national development.

\subsection{Legal Pluralism}

The establishment of a western, mainly English, legal system and the acceptance of other practices condoned or underpinned by local indigenous systems in Nigeria has led to the existence of legal pluralism in Nigeria. Lerner (2011) observed that pluralist legal systems are particularly prevalent in former colonies, where the law of a former colonial authority may exist alongside more traditional legal systems. In the case of Nigeria, the British left the nation deeply divided by ethnic, religious, regional, class, and educational differences (Iwobi, 2004). In the context of legal pluralism, the implied freedom of choice of legal system led most Muslim communities in northern Nigeria to adopt Sharia. Hence, on the basis of their choice, the tendency to keep girl-children out of school was prevalent.

The choice of legal system has significantly influenced the education system and the promotion of children's right to education. The Nigerian girls most affected by the violation of the right to education are generally found in northern states of Borno, Yobe, and Adamawa, where Boko Haram has disrupted academic activities (Iwobi, 2004). 
Apart from the fact that Sharia influences the rights of girl-children to education, northern Nigeria is traditionally a patriarchal society where rigid interpretations of Islam and powerful cultural traditions interact to undermine the rights of women (Bawa, 2017). This culture of patriarchy is a strong determinant of male dominance over women, and, as a result, girls' educational opportunities are usually limited by patriarchal attitudes. Local fundamentalist patriarchies conflate local historical practice with religious dialogue and use subversive interpretations of Islamic law to relegate women to their limited definition of the domestic sphere (Bawa, 2017).

\subsection{Impacts of the Coviod-19 Pandemic}

In the debate about girl-children's right to education, the Covid-19 pandemic came as a spanner in the works. The literature on the impact of the pandemic on girl-children's rights to education is increasing. In less than three months, the disease spread exponentially throughout the world and was declared a pandemic. Obviously, as a pandemic, it has affected all sectors of activity, including educational institutions (World Health Organisation, n.d.). Adeleke, et al. (2021) conducted a study on the impact of Covid-19 in Ondo State, Nigeria. There was already a significant issue with school attendance for children in general and girls in particular. The situation of the Covid-19 pandemic required an adequate methodological approach to grasp the impacts of the problem on the ground. Undertaking a study in Ondo State was the right approach to ascertaining the school attendance problem for girl-children in the state, as there was already the lingering issue of inequality between boys and girls regarding participation in formal education. The methodical approach used, which involved a survey, was adequate in that it revealed factual evidence of the problem of girl-children attendance in a situation of crisis, namely the Covid-19 pandemic. They found that the Covid-19 'lockdown' affected social health, as the majority of the respondents to their survey disclosed that their income had been drastically reduced.

Usman (2020) observed that 'Nigeria contributes approximately $20 \%$ of the global out-of-school population'. Thus, there was a problem ensuring that the children had proper education before Covid-19. However, the impact of the COVID-19 lockdown on school children in Nigeria was profound. The new requirements created by the lockdown were almost impossible for parents and children to meet in terms of access and opportunities. In such a context, the situation of girl-children becomes dire; parents would prefer boys remaining in school and girls dropping out, when parents must make choices regarding access to formal education. This attitude is based on contextual realities underpinned by cultural, traditional, and religious views about women in these societies.

Ogunbambi (2020) stated that many Nigerian students come from vulnerable and disadvantaged backgrounds and do not have access to computers or other learning devices. In many cases, they live in communities with poor or non-existent internet connections. There is also the issue of an unreliable power supply. Students whose families can afford private schools with internet facilities are at an advantage, as virtual learning is available to engage them, but this only increases inequities and inequalities, since the students of government-owned institutions do not have access to such opportunities.

The impacts of Covid-19 on girls' right to education can also be noticed in developing countries other than Nigeria. For instance, in the case of India, Chaudhary observed(2021) that efforts made by authorities over the years to tackle the phenomenon of the deprivation of girl-children of their right to education and the critical progress that has been achieved as a result are being challenged by the outbreak of the COVID-19 pandemic. India, which is considered a developing country, has also been affected by the Covid-19 pandemic. Comparatively, the impacts of the pandemic in both Nigeria and India have evidenced the weakness of systems put in place by authorities to overcome the deprivation of girl-children of their right to education. Chaudhary (2021) noted that up to 10 million girls are at risk of dropping out of secondary school due to the pandemic, and girls are at greater risk of being deprived of their education, as they are pushed towards paid and unpaid labour, as well as into child marriage, in times of crisis. It is likely that many adolescent girls who stop going to school during the pandemic will never return (Chaudhary, 2021). These realities are the norm in many developing countries, such as Nigeria, and they impact the ability of these children to reach the zenith of their immense potential as their progress is prematurely thwarted.

Akintolu et al. (2021) noted that the pandemic has had a significantly gendered impact on children, with girls being pushed out of school. The vast majority of pupils affected by the pandemic are female children in rural areas. Although these rural girls from poor backgrounds were already marginalised, the pandemic has disadvantaged them in terms of access to education, and limited resources and infrastructure do not ensure that learning occurs even at home. The situation of girl-children in the Covid-19 pandemic has unveiled how disadvantaged girl-children are. It has also shown that there is still a considerable amount of work to be done to eradicate the problem. Schools are among the most affected, as is evident in the COVID-19 pandemic, the Boko Haram insurgency, and attacks on communities in Nigeria, which have all compounded the problems many girls face in consistently accessing schooling (Ossai, 2021). Obiwulu (2020) indicated that children of poor households in Nigeria have been forced to quit school and support their families, as COVID-19 has left their parents jobless. This is just one finding of an educational study by the Centre for the Study of the Economies of Africa, an Abuja-based think tank and member of the Southern Voice network of research organisations. 
Azorin (2020) claimed that there is clear evidence that COVID-19 has caused education, as we conceived it before the pandemic, to blow up in the air like an unscheduled fireworks display. This unexpected event has affected most countries. Educational systems have had no choice but to accept the digital checkmate imposed, ranging from telework measures adopted by governments to forced social distancing measures for citizens. This observation is pertinent because it demonstrates how the pandemic has complicated the situation for girl-children already neglected in terms of access to formal education, most especially in developing countries, such as Nigeria, with unsophisticated educational systems together with social-cultural factors already in place before the advent of the pandemic.

The debate about the factors underpinning the deprivation of girl-children of their right to formal education in Nigeria has become monotonous. It appears that scholars and observers have chosen to describe the situation without providing an adequate approach to trigger a paradigm shift. The literature is undoubtedly abundant and rich in terms of the quality of research undertaken, in most cases. However, mere narration of the phenomenon does not suffice to put an end to it. A significant step towards a better evaluation of the problem requires that certain elements be identified. Identification of the common denominator of the problem might constitute an ideal starting point for providing a holistic approach to the question and a permanent solution.

\section{The Common Denominator}

\subsection{The Economic Perspective}

An attempt to identify the common denominator of the factors underpinning the exclusion of girls and women in most societies is worth being made. The move can be regarded as a step in the process of ending the deprivation of girl-children of their right to formal education. The common denominator for the different perceptions held about the exclusion of girls and women in various societies appears to be based on an economic perspective. While the lingering argument is that girls cannot be professionally efficient when they grow up, they are considered sources of revenue in both traditional and modern societies. In situations of extreme poverty, girls are given into marriage with the parents' expectation of receiving a dowry, often comprised of a considerable amount of money and numerous gifts. Babatunde and others stated that it is a known fact that many poor families marry off their daughters at an early age as a strategy for economic survival; it means one less person to feed, clothe, and educate (Afolabi \& Abatan, 2014).

Archer observed that of the 57 million children deprived of formal education globally, 10 million live in Nigeria. This makes Nigeria the country with the highest number of children out of school. The pertinence of this observation is that, in regions where women have a lower social status, many parents opt to send their girls to work in markets rather than to school. However, a lack of education vastly reduces a child's chances of escaping poverty and has led to many girls becoming wives before their 16th birthday (Archer, 2014). This observation unveils the propensity of parents regarding the economic aspect of girls' participation in the community. Indeed, girls are pushed to work in markets in order to bring money to their parents. Their economic value is placed in a short-term perspective, translated by the parents' desire to obtain money or other economic advantages through the girl-children. This argument is reinforced in the British Council's report on girls' education in Nigeria, wherein it was sufficiently demonstrated that, as many families cannot afford the costs of schooling (for uniforms or books), some prefer to send their children to Qur'anic schools or to keep them at home to help with domestic work or to generate additional income (British Council, 2014). The report further revealed that while the costs of schooling may push children out of school, poverty and employment expectations simultaneously curb parents' demand for education, pulling children into various forms of work. In light of these facts, it becomes obvious that parents allow their girl-children to engage in economic activities that can alleviate the state of poverty the whole family endures. It appears, therefore, that the rationale behind barriers to girls' right to formal education involves pretexts to the satisfaction of the immediate economic needs of families. The argument of an economic denominator is pertinent in that the traditional and religious factors that are also blamed for the plight of girl-children rest on the economic perspective.

\subsection{Enduring Paradoxes}

The debate about the deprivation of girl-children of their right to formal education appears to contain an enduring paradox. The parents' argument is that girls cannot assume professional careers. Thus, they prevent girls from accessing formal education. The paradox is that when girls are prevented from accessing formal education on the grounds that they cannot be economically efficient, parents at the same time push them into all types of economic activities to sustain their families. Such an approach appears paradoxical in that while parents deny their girl-children formal education that could lead to a better profession, a stable and better-guaranteed economic situation, they rush them into a much more complex option. Sending girls to work in markets or the streets or pushing them into early marriage for the purpose of receiving a bride price and gifts is an endeavour that rests essentially on an economic rationale. The enduring paradox becomes more apparent through the argument that the economic perspective remains the common denominator for all the barriers or factors underpinning the practice and thus perpetuation of the deprivation of girl-children of their right to formal education. 


\section{New Approaches for an Adequate Response}

\subsection{Current Law and Policy Approaches}

In light of the distortions and disadvantages inflicted on girl-children in northern Nigeria in Sharia and other traditional systems, the federal government has to move towards finding a permanent solution. Indeed, Universal Basic Education, a policy reform measure of the federal government launched in 1999, was intended to rectify distortions in basic education. As such, it would embrace formal education and non-formal equations, including the education of marginalised groups in Nigerian society (Labo-popoola et al., 2009). The reforms indicated efforts by the government to allow all social groups access to education for their children.

From a broader perspective, law and policies on education have been the comprehensive approach to addressing the deprivation of girls of their right to formal education. The National Gender Policy in Basic Education, issued in 2006, was a response to the challenges of achieving gender equality in education, a right expressed in the 1999 Constitution of the Federal Republic of Nigeria, which states that access to quality education is the right of every Nigerian child (Federal Ministry of Education, 2006). The emphasis on girls' right to education is evidenced in the requirement of State Policies and Laws Against Early Marriages and the Girls Scholarship Program for Junior Secondary and Gender Responsive Curriculum. At the state level, informed by the Child Rights Act of 2003, the federal government encourages state governments to enact and enforce state policies and laws which address enduring issues by allowing girls who drop out of school due to pregnancy or other causes to continue with education, prohibiting girl-child marriages or child betrothal, and enforcing laws against the sexual abuse and exploitation of children (Federal Ministry of Education, 2006).

The passing of the Child Rights Act in 2003 signalled Nigeria's intention to protect and preserve the rights of Nigerian children, including girls. The specification in the Child Rights Act that the best interests of the Nigerian child be central to all actions insinuates that the interests of boys and girls must be paramount. In this sense, access to formal education for boys and girls is in their best interests. Hence, the prohibition of both the marriage of those considered children and the betrothal of children by Part III Section 21 (Child Rights Act 2003) evidences the lawmakers' desire to guarantee girl-children rights to formal education in Nigeria.

\subsection{New Paradigms}

New paradigms can be an adequate pedagogical approach to empowering all stakeholders in the question of girl children's education in Nigeria. The call for a new paradigm does not imply that there has not been progress in endeavours to overcome the phenomenon of the deprivation of girl-children of their right to formal education. On that point, Edewor (2006) observed that although the traditional roles of female children and women persist in several spheres, changes are occurring in perceptions of the value of daughters and the status of women in Isoko society. According to Edewor, these changing perceptions are altering the attitudinal disposition of parents towards girl-children in general and girls' education in particular (Edewor, 2006). This observation is pertinent; however, there are several more hurdles to overcome before such changes become widespread among communities throughout Nigeria.

It is obvious that devising policies and setting legal frameworks have not triggered a change of approach to the question of girl children's right to formal education, even though said policies and laws in Nigeria appear to be fit for purpose. Therefore, the problem must be understood from a holistic perspective. Researchers must engage in empirical research based on grounded theory to unveil the magnitude and nature of the phenomenon.

Believing what can be seen, heard, or experienced can be justified by the fact that most hypotheses are validated through empirical research, that empirical research increases human knowledge, and that it continues to advance various fields. There is considerable literature on the question of the deprivation of girl-children of their right to education in Nigeria. However, most research on the question has been undertaken through the method of textual analysis. Textual analysis is often derived from hearsay or previous research and findings. There is no guarantee that these sources are up-to-date and sufficient to allow policymaking or lawmaking or reform. Grounded theory, which would be appropriate in empirical research on the deprivation of girls of their right to formal education, will enable researchers to seek out and conceptualise latent social patterns. It will be concerned with an inductive approach to generating substantive codes from the data collected and later allow the development of theory that will suggest to researchers what proposals should be made to law and policymakers, as well as all stakeholders concerned with the problem of girl's education in Nigeria (Charmaz \& Thornberg, 2021).

In the perspective of a new paradigm, Specific steps must be taken to increase educational opportunities among girls in Nigeria. The steps must be at family level, community level and national level. At family level awareness must be raise to the importance of formal education for girls as it is a mean of empowerment for girls to participate in the family development and socioeconomic stability. Parents must strongly support educating their daughters and have high aspirations both for education and employment. Parents and communities with traditional, strong, negative attitudes 
concerning schooling for girls may in Nigeria must respond to modernising influences currently found only in urban centers in northern Nigeria (Niles, 1989). As to the action of government agencies, there must be campaigns to raise public awareness to the importance of formal education or girls in any society. Its worth noting that according to Sperling, Winthrop, \& kwauk (2016), better-educated women have higher earnings and are able to get and keep better jobs. Particularly in areas where women are not as well represented in the formal economy as men, girls' education can help reduce the gender gap in the labor force. Therefore, Governments agencies and Non Governmental Organisations ( NGOs) must empower community leaders and representatives of parents association to cascade government policies and legales measures in communities. Agencies must educate parents and communities of the fact that laws not only have the purpose of protecting and promoting both boys and girls' rights to formal education but also punishing those who break them. There must also be resources allocated by the federal and local governments to support actions toward the promotion and and protection of girls rights to education in Nigeria. Government agencies and Non Governmental Agencies must encourage mixed schools across Nigeria. However, The building of girls-only schools can be an option for those who may still be reluctant for religious or traditional purpose to send their daughters to mixed schools (Porter, 2016).

\section{Conclusion}

Arguments about the deprivation of girl-children of their right to formal education in Nigeria could last longer than expected and may never end. The existing literature on the issue appears not to have achieved the expected result, namely the elimination of traditional, cultural, and religious considerations that undermine or hinder the chance of girl-children to receive formal education. In the debate, emphasis is also placed on gender inequality. The narrative of gender inequality and the deprivation of girl-children of their right to education is not a novelty. Nonetheless, it creates an 'overload' in the literature without adequately responding to the problem. As indicated by Covell and others, there are indeed many social benefits to providing all children with an education. Although they did not adopt a methodological approach that would address the problem from its roots, their contribution is deemed significant, as they promote inclusiveness in access to formal education and, hence, gender equality.

In most communities in Nigeria, traditional, religious, and cultural considerations have been put forward to explain the prevention of girl-children from receiving a formal education. Where efforts are made to allow girl-children to attend school, they are frequently not permitted to move above the primary level. In terms of expectations in the education cycle, this is insufficient to empower girls and women for effective participation in the socio-economic development of the country. McCowan (2010) argued that, from the perspective of qualifications, a primary school certificate is of little use in a society in which an increasing proportion of people complete secondary school and university. However, he admitted that basic literacy and numeracy skills can be mastered at the primary level, and that they are the threshold for accessing key functioning in society (McCowan, 2010). This redeeming argument is appropriate, as it confirms that the right to education is inalienable; hence, it must be accessed and completed to at least at the primary level. It is proposed that a paradigm shift in approach be adopted. This can be possible if there is an adequate method to identify the problem of the deprivation of girl-children of their right to formal education in Nigeria, and there is an understanding that the core of the problem has, essentially, an economic nature.

\section{References}

Adeleke, O. R. et al. (2021). Impact of Covid-19 pandemic lockdown on social and mental health of Ondo State residents, Nigeria. Middle European Scientific Bulletin, 9(134), 143.

Afolabi, B., \& Abatan, S. M. (2014, November 19). Early Marriage, and Its Implications on the Nigerian Economy. https://doi.org/10.2139/ssrn.2528255

Ahmad, K., \& Mohammad, Y. N. B. (2013). Cultural traditions and practices of the parents as barriers to girl-child education in Zamfara State Nigeria. International Journal of Scientific and Research Publications, 3(1), 8.

Ahmed, M. A. et al. (2015). Enhancing women, girl-child education: A panacea for national development. Proceedings of INTCESS15: 2nd International Conference on Education and Social Sciences, 672, 677.

Akintolu, M. et al. (2021). Exploration of the impact of the COVID-19 on girls' education in Nigeria. African Journal of Gender, Society and Development, 10(2), 59, 75. https://doi.org/10.31920/2634-3622/2021/v10n2a4

Archer, D. (2014, May 15). Nigeria's girls and the struggle for an education in the line of fire. The Guardian.

Azorın, C. (2020). Beyond COVID-19 supernova. Is another education coming? Journal of Professional Capital and Community, 1. https://doi.org/10.1108/JPCC-05-2020-0019

Balarabe, B. A. (2017). Muslim women and Sharia implementation in northern Nigeria: An overview of Fomwan. UJAH, 18(149), 167. https://doi.org/10.4314/ujah.v18i1.8 
British Council. (2014). Girls' Education in Nigeria (Report).

Charmaz, K., \& Thornberg, R. (2021). The pursuit of qualitative grounded theory. Qualitative Research Psychology, 18(305), 327. https://doi.org/10.1080/14780887.2020.1780357

Chaudhary, M. (2021, July 11). COVID-19 rolls back progress on female education in India. EASTASIAFORUM Child Rights Act 2003.

Edewor, P. A. (2006). Changing perceptions of the value of daughters and girls' education among the Isoko of Nigeria. African Population Studies, 21(55), 70. https://doi.org/10.11564/21-1-350

Godiya, A. M. (2013). Patriarchy and gender inequality in Nigeria: The way forward. European Scientific Journal, 9(115), 144.

Labo-popoola et al. (2009). Universal basic education in Nigeria: Challenges and way forward. The Social Sciences, 4.

McCowan, T. (2010). Reframing the universal right to education. Comparative Education, 46(509), 525. https://doi.org/10.1080/03050068.2010.519482

Natan, L. (2011). Group rights and legal pluralism. Emory International Law Review, 25(2).

National Policy on Gender in Basic Education, 2006. Retrieved January 24, 2021, from https://planipolis.iiep.unesco.org/sites/default/files/ressources/nigeria_policy_gender_basic_education.pdf

Niles, F. S. (1989). Parental Attitudes toward Female Education in Northern Nigeria. The Journal of Social Psychology, 129(1), 13, 20. https://doi.org/10.1080/00224545.1989.9711694

Obinna, O. (2020, December 8). Nigeria's Children: Covid-19 and Broken Dreams. Retrieved January 22, 2022, from https://www.newsbreak.com/news/2121411594363/nigeria-s-children-covid-19-and-broken-dreams

Ofoha, D. (2013). Gender stereotypes and girl-child education in Nigeria. National Open University of Nigeria. Retrieved January 23, 2022, from http://oasis.col.org/handle/11599/2044

Ogunbambi, T. (2020). COVID 19 Lockdown: Impact on Girl's Education in Nigeria. This day, Lagos. Retrieved January 23,2022 , from https://www.thisdaylive.com/index.php/2020/05/13/covid-19-lockdown-impact-on-girls-education-in-nigeria/

Olawale, S. K. D. (2016). Islamic perspectives on western education. Journal of Islamic Studies in Indonesia and Southeast Asia, 1(185), 1997.

Ossai Eden Dorothy. (2021). Mesmar Danny (Education in Emergency in Nigeria: Creating Gender Equitable Policies So All Girls Have an Uninterrupted Right to Learn. Retrieved January 22, 2022, from https://www.gesseducation.com/industry-news/education-in-emergency-in-nigeria-creating-gender-equitable-polici es-so-all-girls-have-an-uninterrupted-right-to-learn?page $=162$

Oyigbenu, A. (2010). Girl-child education and Nigeria's development agenda: A literary perspective. An International Multi-Disciplinary Journal, 4(416), 432. https://doi.org/10.4314/afrrev.v4i2.58353

Pai, O. (2004). Education for the knowledge of economy (Mosure Publishers).

Porter, S. A. (2016). Girls' education, development and social change: 'Seeding, Strengthening and Linking' (Global Fund for Women). Policu Futre in Education, 14(5), 517, 538. https://doi.org/10.1177/1478210315625904

Sa'ad, T. et al. (2018). Education for all in Nigeria, West Africa: The journey so far. KIU Journal of Social Sciences, 4(2), $205,212$.

Sperling, G. B., Winthrop, R., \& Kwauk, C. (2016) What Works in Girls' Education Evidence for the World's Best Investment. Washington, D.C.: The Brookings Institution.

Ubaka, I. A. (2004). Tiptoeing through a constitutional minefield: The great Sharia controversy in Nigeria. Journal of African Law, 48(111), 114. https://doi.org/10.1017/S0021855304482023

UNESCO. (2015). Empowering Adolescent Girls and Young Women through Education. Retrieved from https://unesdoc.unesco.org/ark:/48223/pf0000231944

UNICEF. Inclusive education: Every child has the right to quality education and learning. Retrieved from https://www.unicef.org/education/inclusive-education 
Usman, J. A. (2020). The impact of Covid-19 on the educational development in Nigeria. Al-Hikmah Journal of Educational Management and Counselling, 2(31), 39.

\section{Copyrights}

Copyright for this article is retained by the author(s), with first publication rights granted to the journal.

This is an open-access article distributed under the terms and conditions of the Creative Commons Attribution license which permits unrestricted use, distribution, and reproduction in any medium, provided the original work is properly cited. 